\title{
Evaluation of Effect of Inverse and Field-in-Field IMRT Planning for Left-Sided Anterior Descending Coronary Artery Doses in Left-Sided Breast Cancer Patients
}

\author{
Esil KARA, ${ }^{1}$ Müge AKMANSU, ${ }^{2}$ Bahar DiRiCAN, ${ }^{3}$ Aslı YAZICI ${ }^{1}$ \\ 'Department of Radiation Oncology, ONKO Ankara Oncology Center, Ankara-Turkey \\ ${ }^{2}$ Department of Radiation Oncology, Gazi University, Ankara-Turkey \\ 'Department of Radiation Oncology, Gülhane Training and Research Hospital, Ankara-Turkey
}

\begin{abstract}
OBJECTIVE
The aim of the study is to evaluate radiation doses of left-sided whole-breast irradiation on left-sided anterior descending coronary artery (LAD) among various radiotherapy treatment planning techniques for 45 left-sided breast cancer patients.

\section{METHODS}

Three different radiotherapy techniques, field-in-field, 4-field inverse IMRT, and 5-field IMRT, were undertaken. For inverse IMRT, the fields were special for each patient. We used 2 opposed tangential beams in the field-in-field technique, and for the other two techniques, the beams were obtained by $10^{\circ}$ refraction.
\end{abstract}

\section{RESULTS}

The 5-field IMRT technique is not useful for decreasing the LADmax dose. We figured out that in the field-in-field technique, 18 of our 45 patients received doses greater than 10 Gy to LAD. We also found that using the 4 -field inverse IMRT technique, LAD and lung doses could be reduced.

\section{CONCLUSION}

The mean LADmax dose was smaller than $10 \mathrm{~Gy}$ for all techniques except the field-in-field technique. There was no significant difference between 4 -field inverse IMRT and field-in-field techniques. However, if LAD is located deeper than $2.5 \mathrm{~cm}$, the LADmax dose could increase; this could further be decreased to under 10 Gy using the 4-field inverse IMRT technique.

Keywords: IMRT; left Breast Cancer; LAD; radiotherapy.

Copyright $\odot$ 2018, Turkish Society for Radiation Oncology

\section{Introduction}

Breast cancer is the most common cancer among women worldwide.[1] Radiation therapy (RT) plays an important role in the treatment of breast cancer. A meta-analysis, including nearly 42.000 women, showed that the local control, breast cancer-specific survival, and overall survival could be improved using RT after mastectomy or lumpectomy.[2] Unfortunately, the same Oxford metaanalysis also showed that using RT for breast cancer is related to a hazard ratio pertaining to death secondary to heart disease. [2,3] There have been many studies indicating that patients with breast cancer who received RT had a higher risk of cardiac disease and/or death compared with those treated by surgery alone.[4,5] Previous studies also showed that those who were irradiated for left-sided 
breast cancer had a higher risk of cardiac disease and/or death compared with those who were irradiated for rightsided breast cancer.[4,6] In some studies, the incidence of cardiac events was low in the first 5 years of follow-up, and it increased over time and persisted after year 18.[4,6] The study by Nilssons et al [7] suggested that RT for breast cancer increases the risk of cardiovascular diseases, including pericarditis, coronary artery disease (CAD), conduction abnormalities, congestive heart failure, and valvular disease. Radiation exposure to the left-sided anterior descending coronary artery (LAD) is a major cause of these complications.

Recent studies show that the number of patients with heart disease after RT has now decreased compared with that in previous decades.[8] By developing technologies (such as IMRT, breath-hold technique, and active breath control), the risk of CAD could be reduced with the decrease in the maximum LAD (LADmax) dose.

Field-in-Field (FIF) intensity-modulated radiotherapy (IMRT) is presently the most commonly used technique. Two opposed tangential fields are generally chosen to cover the entire breast. Similar beam orientations to 3D-CRT are utilized, but additional fields are used to block hotspots instead of wedges to improve the dose homogeneity. Another chosen technique is inverse IMRT offering the ability to provide more options in the planning process. [9] It allows more homogeneous dose distribution and low organ at risk (OAR) dose.

In this study, we aimed to evaluate various radiotherapy treatment planning techniques and their effects on LAD doses. For this purpose, we compared field-in-field IMRT, 4-field inverse IMRT, and 5-field inverse IMRT radiation doses to LAD among 45 left breast cancer patients. During this study, we realized that if LAD is closer than $2.5 \mathrm{~cm}$ from the pectoral muscle, the LADmax dose increases irrespective of the radiotherapy technique.

\section{Materials and Methods}

Forty five consecutive left-sided early breast cancer patients ranging from 32 to 76 years of age were examined in this study. All the patients underwent breast-conserving surgery and were irradiated after lumpectomy. None of the patients were irradiated post-mastectomy. All the patients had and outer quadrant tumor so that none of the irradiated volumes included the inner quadrant. Immobilization and CT simulation were performed for 45 left-sided breast cancer patients, as is routine for breast cancer patients receiving IMRT in our department. The patients received free-breathing CT scans. We could not conduct 4D-CT scans for the deep-inspiration breathhold technique; furthermore, our study was retrospective.
The treatment position was supine with breast board. Using the simulator lasers, patients were aligned and marked to define the coordinate system to be used for treatment planning. The patients were scanned in treatment position on Siemens Emotion Duo using 5-mm slice thickness. The data were transferred to the treatment planning system (Prowess Panther DAQ). The determination of the 45 breast cancer patient's target volume and critical tissues was initially done using CT images obtained in our clinic.

After determining the critical organs, which were the left lung, heart, LAD, and contralateral breast, three different radiotherapy techniques, field-in-field IMRT, 4-field inverse IMRT, and 5-field IMRT, were performed. The initial calculation of the field-in-field technique was performed with two equally weighted, open, tangential photon beams. Hot-spot volumes blocking two or three subfields were determined to improve dose homogeneity while decreasing overdoses in PTV. The main field and the subfields were merged into one portal.

For 4-field inverse IMRT, the fields were special for each patient. We used two opposed tangential beams for the field-in-field technique, and for the other techniques, beams were obtained by placing them at a $10^{\circ}$ refraction angle.

Finally, for the 5-field IMRT technique, we chose $300^{\circ}$, $330^{\circ}, 30^{\circ}, 120^{\circ}$, and $150^{\circ}$ beam angles for optimization.

After obtaining the IMRT plans, we dosimetrically compared the doses of OARs. We also tried to determine the critical distance from the chest wall to LAD causing an increase in the LADmax dose. After figuring out this distance, we studied the doses of OAR's smaller distances than this critical distance.

The Statistical Package for Social Sciences (SPSS) version 22.0 was used for statistical analysis (SPSS Inc. Chicago, II., USA). Paired samples t-test was used for comparisons. A p value of $<0.05$ was considered to be significant.

\section{Results}

After performing the techniques for the first 5 patients, we figured out that the 5-field inverse IMRT technique is not useful for decreasing the LADmax dose. Ipsilateral lung and heart LADmax doses significantly increased using the 5-field inverse IMRT technique because of the $30^{\circ}$ field. Therefore, we decided not to use this technique for the rest of our study.

Then, we compared doses of OARs leading to maximum doses of $\mathrm{LAD}, 25 \%$ dose of ipsilateral lung, 5\% dose of heart, and mean dose of contralateral breast for fieldin-field IMRT and 4-field inverse IMRT techniques. We 


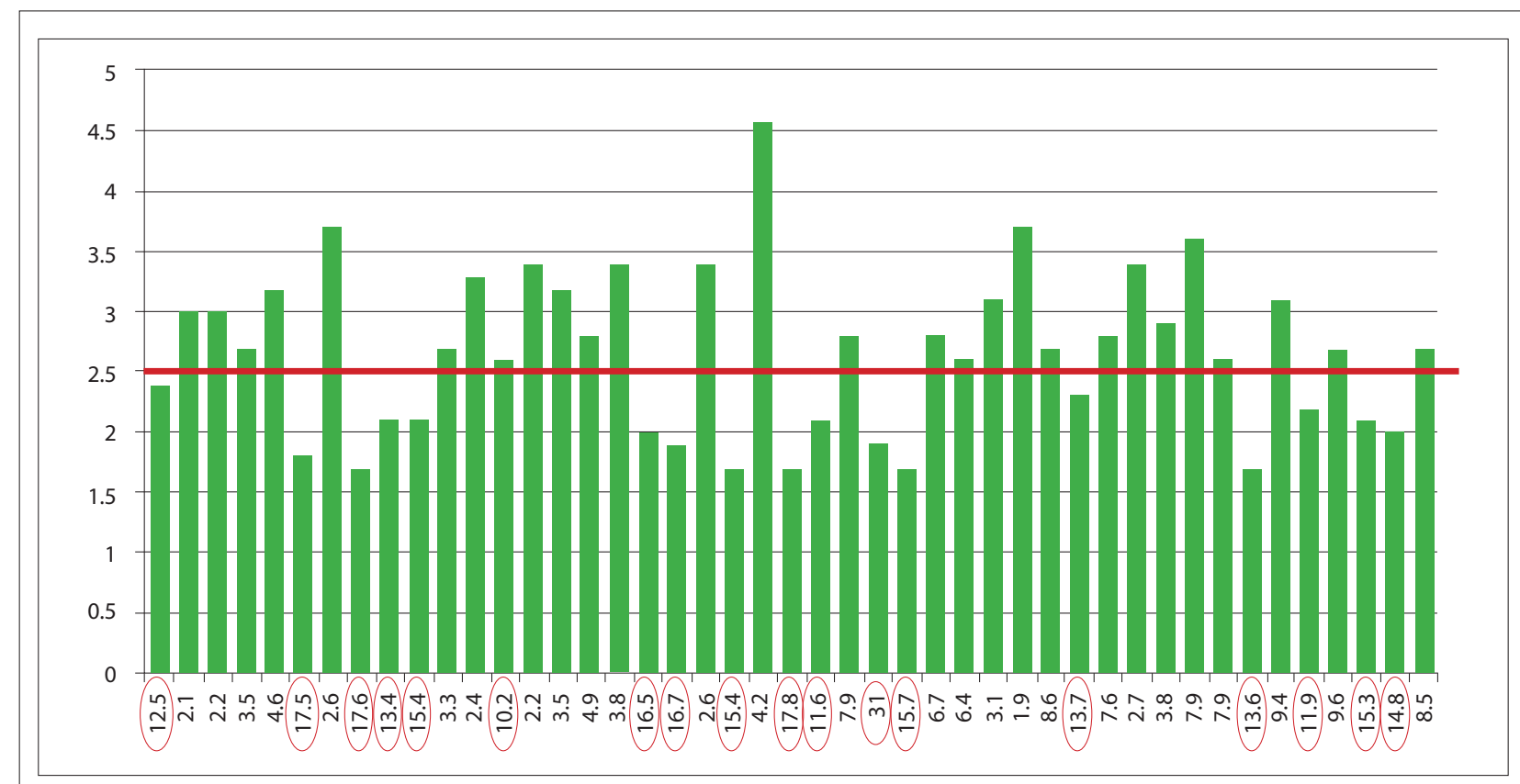

Fig. 1. Distance versus LAD max graph. Red line shows $2.5 \mathrm{~cm}$ distance from the chest wall to LAD.

Table 1 Doses and $p$ values of OAR * $p<0.05$, statistically significant

\begin{tabular}{lccc} 
Parameter & FIF IMRT & 4 field IMRT & $\boldsymbol{P}$ \\
\hline LAD $_{\max }$ & $9.42 \pm 6.86$ & $7.39 \pm 2.64$ & 0.231 \\
Ipsilateral Lung (\%25) & $5.39 \pm 5.39$ & $5.68 \pm 5.89$ & 0.578 \\
Ipsilateral Lung (mean) & $6.23 \pm 3.83$ & $6.08 \pm 4.36$ & 0.963 \\
Heart (\%5) & $23.5 \pm 18.18$ & $24.9 \pm 5.39$ & 0.635 \\
Heart (mean) & $3.68 \pm 2.65$ & $4.05 \pm 3$ & 0.526 \\
Contralateral Breast (mean) & $0.28 \pm 0.73$ & $1.52 \pm 1.06$ & $0.04^{*}$
\end{tabular}

used Quantitative Analyses of Normal Tissue Effects in the Clinic (QUANTEC) recommendations for dose-volume comparisons.

The doses and standard deviations (SDs) of OAR are shown in Table 1. The mean doses of the contralateral breast were significantly increased with inverse the IMRT technique ( $p$ value of $<0.05$ for breast). There were no significant changes in the LADmax for the ipsilateral lung (25\%) and heart (5\%) with the 4-field inverse IMRT technique ( $\mathrm{p}$ value $>0.05$ ).

Second, we figured out from our study that there is a relation between the distance from pectoral muscle to LAD and the LADmax dose.

As can be seen in Figure 1, if the distance from pectoral muscle to LAD is less than $2.5 \mathrm{~cm}$, the LADmax dose could be greater than 10 Gy. In our study, 18 of our 45 patients had an LADmax dose greater than 10 Gy. Only one of these patients had a pectoral muscle to LAD distance greater than $2.5 \mathrm{~cm}$. As a result of these findings,
Table 2 Doses and $p$ values of OAR for 18 patients having a chest wall to LAD distance lesser than $2.5 \mathrm{~cm}$

\begin{tabular}{lccc} 
Parameter & FIF IMRT & 4 field IMRT & $\boldsymbol{P}$ \\
\hline Ipsilateral Lung (\%25) & $13.5 \pm 4.65$ & $8.26 \pm 3.1$ & 0.025 \\
Heart (\%5) & $26.3 \pm 4.61$ & $19.5 \pm 5.02$ & $<0.001$ \\
Heart (mean) & $3.68 \pm 2.65$ & $4.05 \pm 3$ & 0.526 \\
Contralateral Breast (mean) & $0.32 \pm 0.24$ & $1.53 \pm 0.35$ & 0.04 \\
\hline
\end{tabular}

we decided to perform paired sample t-test using SPSS (between FIF and inverse IMRT) on LADmax doses in which LAD was located not deeper than $2.5 \mathrm{~cm}$. The $p$ value was smaller than 0.05 , implying that the change in the LADmax dose was significantly decreased by 4 -field inverse IMRT.

Our results indicated that ipsilateral lung and heart doses were significantly decreased $(\mathrm{p}<0.05)$ by inverse IMRT, while contralateral breast dose significantly increased for the 18 patients $(\mathrm{p}<0.05)$ in whom the chest wall to LAD distance was greater than $2.5 \mathrm{~cm}$ (Table 2).

\section{Discussion}

RT plays an important role in the treatment of breast cancer. Unfortunately, it also a dark side like secondary heart disease. A significant increase in mortality from heart disease, that is sustained 18 years following RT to the left-sided breast, has been demonstrated in previous studies. $[5,10]$ The right coronary artery (RCA) and leftsided main coronary artery (LMCA) arise from the aorta 
near its root. The LMCA bifurcates into LAD artery and the left circumflex artery. Radiation exposure of the left is a major cause of these complications. A previous study showed that in the event of LAD doses greater than $10 \mathrm{~Gy}$, the probability of CAD increases.[11] Radiation tolerance of the coronary arteries has not been well-studied until recently. Historically, the dose-volume histogram (DVH) has been used for the heart as an organ.[12] The heart is a "serial-parallel" organ. Because the myocardium is a parallel organ, small volume of the heart can tolerate even higher dose levels. Coronary arteries are in fact a "serial" organs like spinal cord.[13] Any partial damage to the coronary artery will cause potential devastating toxicity even if the rest of the artery is not irradiated. Therefore, heart DVH determinations are of little use to estimate the risk of CAD.[14] There are only few studies that address whether RT acts additively with known CAD risk factors such as smoking, hypercholesterolemia, hypertension, and diabetes mellitus.[5,6]

In an effort to better define radiation-associated cardiac toxicity, Darby et al. published a study in 2005 in which they compared cardiac mortality for women who received radiation for left-sided versus right-sided breast cancer and found that radiation for left-sided sided breast cancer increased the risk of cardiac disease and death.[15] In 2013, Darby et al. published a case-controlled study analyzing the risk of major coronary events and again found that women with left-sided sided breast cancer had more major coronary events than those treated for right-sided breast cancer.[5] In this literature, rates of major coronary events increased linearly with the mean dose to the heart by $7.4 \%$ per gray ( $95 \%$ confidence interval, 2.9 to 14.5 ; $\mathrm{p}<0.001$ ), and the CAD risk started within 5 years after radiotherapy and continued into the third decade after radiotherapy.

According to a review, which collected all data from 2003 to 2013, if the treatment volume did not include the internal mammary chain (IMC), average mean heart dose was $4.2 \mathrm{~Gy}$, and this value varied with the irradiated target tissues. For IMRT, the mean heart dose was approximately $5.6 \mathrm{~Gy}$. Where the IMC was irradiated average mean heart dose was around $8 \mathrm{~Gy}$ and varied little according to other irradiated targets.[16] Jöst et al. suggest using IMRT and volumetric modulated arc radiotherapy (VMAT) technique together for decreasing the heart doses.[17] In our study, heart doses changed due to different radiation treatment techniques, as can be seen in Table 1 .

In some new researches, intraoperative radiotherapy can be used in early-stage breast cancer.[18,19] In these studies LAD doses are lower than the external irradiation doses, but Darby et al. suggest that special attention must be given to valvular disease in this situation. In the near future, if we continue to give external radiotherapy to the patients, we should pay extra attention not only to heart doses but also to LAD doses. Prone positions or the semi-decubitus technique have been used to exclude the heart from additional irradiation fields in many patients. $[20,21]$ However, in some author series, incidental dose to the coronary arteries is higher in prone than in supine whole-breast irradiation.[22] Respiratory gating, which means intermittent irradiation synchronous with the free breathing cycle and administered in the supine position, should be further analyzed.

In our study, we have tried to determine radiation doses among various radiotherapy treatment planning techniques; field-in-field IMRT and inverse IMRT for 45 left-sided breast cancer patients. As can be seen in Table 1 , the mean LADmax dose was smaller than $10 \mathrm{~Gy}$. There is no significant difference between 4-field inverse IMRT and field-in-field techniques. However, the patients' in whom the chest wall to LAD distance was smaller than $2.5 \mathrm{~cm}$, the LADmax dose was higher than $10 \mathrm{~Gy}$.

Unfortunately, by reducing the LADmax dose, the contralateral breast dose could be increased with only the 4 -field inverse IMRT technique. This is another important point to be aware of. In our study, we investigated whether or not the LAD doses can be reduced for patients in whom LAD is located not deeper than $2.5 \mathrm{~cm}$ using 4-field inverse IMRT. The lung and heart doses can also be reduced using this technique.

\section{Conclusion}

Previous studies have shown that in the event of LAD doses greater than $10 \mathrm{~Gy}$, the probability of CAD is increased. In our study, we tried to figure out radiation doses of LAD among various radiotherapy treatment planning techniques for 45 left breast cancer patients retrospectively. There is no a significant difference between 4-field inverse IMRT and field-in-field IMRT. However, we could not use the 4D irradiation technology for breast radiotherapy. If LAD is located closer than $2.5 \mathrm{~cm}$ from the pectoral muscle, the dose of LADmax could increase and could be decreased under 10 Gy using 4-field inverse IMRT. The lung and heart doses can also be reduced using this technique. In conclusion, LAD doses can be reduced with various IMRT techniques, and future prospective studies should be conducted using the $4 \mathrm{D}$ breast irradiation technology.

Peer-review: Externally peer-reviewed.

Conflict of Interest: None declared.

Authorship contributions: Concept - M. A; Design - M. A; Supervision - B. D; Materials - E. K; Data collection \&/or pro- 
cessing - E. K; Analysis and/or interpretation -B. D; Literature search - A. Y; Writing - E. S; Critical review - M. A

\section{References}

1. Jemal A, Bray F, Center MM, Ferlay J, Ward E, Forman D. Global cancer statistics. CA Cancer J Clin 2011;61(2):6990. [CrossRef]

2. Clarke M, Collins R, Darby S, Davies C, Elphinstone P, Evans V, et al; Early Breast Cancer Trialists' Collaborative Group (EBCTCG). Effects of radiotherapy and of differences in the extent of surgery for early breast cancer on local recurrence and 15-year survival: an overview of the randomised trials. Lancet 2005;366(9503):2087-106.

3. Brown LC, Mutter RW, Halyard MY. Benefits, risks, and safety of external beam radiation therapy for breast cancer. Int J Womens Health 2015;7:449-58.

4. Sardaro A, Petruzzelli MF, D'Errico MP, Grimaldi L, Pili G, Portaluri M. Radiation-induced cardiac damage in early left breast cancer patients: risk factors, biological mechanisms, radiobiology, and dosimetric constraints. Radiother Oncol 2012;103(2):133-42. [CrossRef]

5. Darby SC, Ewertz M, McGale P, Bennet AM, BlomGoldman U, Brønnum D, et al. Risk of ischemic heart disease in women after radiotherapy for breast cancer. $\mathrm{N}$ Engl J Med. 2013;368(11):987-98. [CrossRef]

6. Hooning MJ, Botma A, Aleman BM, Baaijens MH, Bartelink H, Klijn JG, et al. Long-term risk of cardiovascular disease in 10-year survivors of breast cancer. J Natl Cancer Inst 2007;99(5):365-75. [Crossef]

7. Nilsson G, Holmberg L, Garmo H, Duvernoy O, Sjögren I, Lagerqvist B, et al. Distribution of coronary artery stenosis after radiation for breast cancer. J Clin Oncol 2012;30(4):380-6. [CrossRef]

8. Giordano SH, Kuo YF, Freeman JL, Buchholz TA, Hortobagyi GN, Goodwin JS. Risk of cardiac death after adjuvant radiotherapy for breast cancer. J Natl Cancer Inst 2005;97(6):419-24. [CrossRef]

9. Schubert LK, Gondi V, Sengbusch E, Westerly DC, Soisson ET, Paliwal BR, et al. Dosimetric comparison of left-sided whole breast irradiation with 3DCRT, forward-planned IMRT, inverse-planned IMRT, helical tomotherapy, and topotherapy. Radiother Oncol 2011;100:241-6. [CrossRef]

10. Marks LB, Yorke ED, Jackson A, Ten Haken RK, Constine LS, Eisbruch A, et al. Use of normal tissue complication probability models in the clinic. Int J Radiat Oncol Biol Phys 2010;76(3 Suppl):S10-9. [CrossRef]

11. Baker JE, Fish BL, Su J, Haworth ST, Strande JL, Komorowski RA, et al. 10 Gy total body irradiation increases risk of coronary sclerosis, degeneration of heart structure and function in a rat model. Int J Radiat Biol 2009;85(12):1089-100. [CrossRef]

12. Pezner RD. Coronary artery disease and breast radiation therapy. Int J Radiat Oncol Biol Phys 2013;86(5):816-8.

13. International Commission on Radiation Units and Measurements. ICRU Report 62; 1999. Available at: https:// academic.oup.com/jicru/article-abstract/os32/1/NP/292 4047? redirectedFrom=fulltext. Accessed Jan 10, 2018.

14. Taylor CW, Povall JM, McGale P, Nisbet A, Dodwell D, Smith JT, et al. Cardiac dose from tangential breast cancer radiotherapy in the year 2006. Int J Radiat Oncol Biol Phys 2008;72(2):501-7. [CrossRef]

15. Darby SC, McGale P, Taylor CW, Peto R. Long-term mortality from heart disease and lung cancer after radiotherapy for early breast cancer: prospective cohort study of about 300,000 women in US SEER cancer registries. Lancet Oncol 2005;6(8):557-65. [CrossRef]

16. Taylor CW, Wang Z, Macaulay E, Jagsi R, Duane F, Darby SC. Exposure of the Heart in Breast Cancer Radiation Therapy: A Systematic Review of Heart Doses Published During 2003 to 2013. Int J Radiat Oncol Biol Phys 2015;93(4):845-53. [CrossRef]

17. Jöst V, Kretschmer M, Sabatino M, Würschmidt F, Dahle $\mathrm{J}$, Ueberle F, et al. Heart dose reduction in breast cancer treatment with simultaneous integrated boost: Comparison of treatment planning and dosimetry for a novel hybrid technique and 3D-CRT. Strahlenther Onkol 2015;191(9):734-41. [CrossRef]

18. Vaidya JS, Bulsara M, Wenz F. Ischemic heart disease after breast cancer radiotherapy. $\mathrm{N}$ Engl $\mathrm{J}$ Med 2013;368(26):2526-7.

19. Chan TY, Tan PW, Tan CW, Tang JI. Assessing radiation exposure of the left anterior descending artery, heart and lung in patients with left breast cancer: A dosimetric comparison between multicatheter accelerated partial breast irradiation and whole breast external beam radiotherapy. Radiother Oncol 2015;117(3):459-66. [CrossRef]

20. Formenti SC, DeWyngaert JK, Jozsef G, Goldberg JD. Prone vs supine positioning for breast cancer radiotherapy. JAMA 2012;308(9):861-3. [CrossRef]

21. Niglas M, McCann C, Keller BM, Makhani N, Presutti J, Vesprini D, et al. A dosimetric study of cardiac dose sparing using the reverse semi-decubitus technique for left breast and internal mammary chain irradiation. Radiother Oncol 2016;118(1):187-93. [CrossRef]

22. Würschmidt F, Stoltenberg S, Kretschmer M, Petersen C. Incidental dose to coronary arteries is higher in prone than in supine whole breast irradiation. A dosimetric comparison in adjuvant radiotherapy of early stage breast cancer. Strahlenther Onkol 2014;190(6):563-8.

23. Schubert LK, Gondi V, Sengbusch E, Westerly DC, Soisson ET, Paliwal BR, et al. Dosimetric comparison of left-sided whole breast irradiation with 3DCRT, forward-planned IMRT, inverse-planned IMRT, helical tomotherapy, and topotherapy. Radiother Oncol 2011;100(2):241-6. [CrossRef] 